\title{
Correction to: COVID-19 and Similar Futures: Pandemic Geographies
}

\author{
Gavin J. Andrews, Valorie A. Crooks, Jamie R. Pearce,
} and Jane P. Messina

\section{Correction to: \\ G. J. Andrews et al. (eds.), COVID-19 and Similar Futures, Global Perspectives on Health Geography, https://doi.org/10.1007/978-3-030-70179-6}

\section{Chapter 48}

An error in the production process unfortunately led to publication of this chapter prematurely, before incorporation of the final corrections. The version supplied here has been corrected and approved by the authors.

\section{Chapter 9}

The original version of this chapter was inadvertently published with the author's name listed as "Josh Evans." It has now been updated to "Joshua Evans" in the chapter opening page \& table of contents.

\section{Chapter 37}

The original version of this chapter was inadvertently published with the second author's name incorrectly spelled as "Marco Garrido Cumbrera". The author's name has now been updated as "Marco Garrido-Cumbrera" in chapter opening page \& table of contents.

\footnotetext{
The updated online versions of the chapters can be found at https://doi.org/10.1007/978-3-030-70179-6_9 https://doi.org/10.1007/978-3-030-70179-6_37 https://doi.org/10.1007/978-3-030-70179-6_41 https://doi.org/10.1007/978-3-030-70179-6_48
} 


\section{Chapter 41}

The original version of this chapter was inadvertently published with the chapter author name incorrectly spelled as "Beth Greenbough". The author name has now been updated as "Beth Greenhough" in chapter opening page \& table of contents. 